ARTICLE

https://doi.org/10.1057/s41599-019-0325-7

\title{
The tail wagging the dog: positive attitude towards livestock guarding dogs do not mitigate pastoralists' opinions of wolves or grizzly bears
}

Daniel Kinka ${ }^{1} \&$ Julie K. Young ${ }^{1,2 \star}$

\begin{abstract}
While the re-establishment of grizzly bears (Ursus arctos) and wolves (Canis lupus) in the American West marks a success for conservation, it has been contentious among pastoralists. Coincidentally, livestock guarding dogs (LGDs; Canis familiaris) have been widely adopted by producers of domestic sheep (Ovis aries) in the United States to mitigate livestock depredation by wild carnivores. We surveyed pastoralists to measure how experience with and attitudes towards LGDs related to attitudes towards livestock predators, and found positive responses regarding LGDs and negative responses regarding wolves and grizzly bears. The more respondents agreed that LGDs reduce the need for lethal management $(p<0.01)$ and prevent the spread of disease $(p<0.05)$, the more positive their opinion of wolves in the wild. Regarding wolves and livestock, respondents who disagreed with the statements that "LGDs do more harm than good" $(p<0.05)$ or "reduce the need for lethal management" $(p<0.001)$, were more likely to express more negative opinions of wolves. While results pertaining to a reduced need for lethal management may suggest LGDs have some ability to increase tolerance for wolves, the causal order of these effects is difficult to discern. A more positive attitude for wolves to begin with may predict more optimistic attitudes about the capacity of LGDs to reduce human-wildlife conflict. We found almost no support for the opinion that LGDs do more harm than good, even though attitudes towards wolves were generally negative. Respondents with up to 10 years' experience using LGDs had more negative attitudes towards grizzly bears $(p<0.01)$ and respondents with more than 10 years' experience using LGDs had the most negative attitudes towards grizzly bears ( $p<$ 0.001). Thus, while experience was the greatest predictor of attitudes towards grizzly bears, attitudes towards wolves were most correlated with the belief that LGDs offset the need for lethal management of carnivores. These results suggest that LGD use in the United States does not seem to have resulted in more positive attitudes about livestock predators amongst pastoralists.
\end{abstract}

\footnotetext{
${ }^{1}$ Department of Wildland Resources, Utah State University, 5230 Old Main Hill, Logan, UT 84322-5230, USA. ${ }^{2}$ USDA - WS - National Wildlife Research Center - Predator Research Facility, Millville, UT 84326, USA. *email: julie.k.young@usda.gov
} 


\section{Introduction}

arge carnivores are unique among other animals in terms of their ability to elicit strong emotions; they can be a contentious socioecological issue (Shivik, 2006; Gehring et al., 2010). While the reintroduction of gray wolves (Canis lupus) and the re-establishment of grizzly bears (Ursus arctos) in the Northern Rocky Mountains of the United States (US) marked a success for conservationists, it also raised real and perceived concerns of risk among many pastoralists who cope with livestock depredation by wolves and grizzly bears (USDA, 2015). Lethally managing carnivores to reduce livestock depredations is commonly used (Fritts et al., 2003; Bradley et al., 2015) but socially unpopular (Bergstrom, 2017; Slagle et al., 2017), questionable in its effectiveness (Berger, 2006), and not as broadly applicable for species of concern like wolves and grizzly bears due to Federal endangered species protections. These factors may partially explain the rapid adoption of non-lethal tools, such as livestock guarding dogs (LGDs; also known as livestock guardian dog, livestock guard dog, and livestock protection dog), as a means of reducing livestock depredations in North America (Gehring et al., 2010).

LGDs are domestic dogs (Canis familiaris) of a few dozen breeds that have been bred and trained to protect livestock from depredation, injury, and theft. LGDs are effective at reducing depredations by a suite of carnivores, including coyotes (Canis latrans; Andelt and Hopper, 2000), dingoes (C. lupus dingo; van Bommel and Johnson, 2012), black bears (Ursus americanus; Smith et al., 2000), and cheetahs (Acinonyx jubatus; Marker et al., 2005). LGD effectiveness at reducing depredations from other large North American carnivores, such as wolves, grizzly bears, and cougars (Puma concolor), has been suggested but not empirically tested (but see Kinka and Young, 2019). LGDs enjoy a rich tradition in European history that dates back at least 5000 years (Smith et al., 2000; Rigg, 2001; Coppinger and Coppinger, 2002; Gehring et al., 2010) but were first imported to the US in the 1970s as a substitute for lethal predator control outlawed by the Endangered Species Act (Feldman, 2007). Since that time, the use of LGDs as a non-lethal management tool for reducing livestock depredations has been widely adopted by domestic sheep producers in the US because they are one of the few nonlethal management techniques that reduce domestic sheep (Ovis aries) depredations (Andelt and Hopper, 2000; Smith et al., 2000; Hansen et al., 2002; van Bommel and Johnson, 2012; Miller et al., 2016) and provide long-term results (Shivik, 2006), despite some recent evidence to the contrary (Eklund et al., 2017). With the reintroduction of wolves to the Rocky Mountains and the recovery of other large carnivore populations, new breeds of LGDs are being introduced in the US for use deterring large predators as well (Kinka and Young, 2018).

One aspect of LGD use that has gone largely unstudied is whether their use mediates pastoralists' tolerance for livestock predators. For instance, Rust et al. (2013) detected an increase in reported tolerance for cheetahs in 11 of 14 South African farmers after they began using LGDs. Other studies have evaluated the perceived effectiveness of LGDs, and while they were able to show that LGDs were perceived to be highly effective or moderately effective, they did not test for a mediating effect of LGDs on tolerance for large carnivores (Marker et al., 2005; Scasta et al., 2017). There have also been a number of studies on human attitudes towards large carnivores that do not address LGDs (Suryawanshi et al., 2013; Dressel et al., 2014; Young et al., 2015; Berry et al., 2016; Knopff et al., 2016; Miller et al., 2016). For instance, encounter rate is the strongest predictor of perceived depredation risk from wolves (Suryawanshi et al., 2013), while willingness to adopt non-lethal management strategies and coexist with wolves is correlated with length of exposure and experience with wolves (Young et al., 2015). However, some of these studies lack a well-developed framework for assessing tolerance of large carnivores, failing to incorporate psychosocial theory on how attitudes arise and persist (Kalberg, 1980; Fishbein and Ajzen, 2009; Zajac et al., 2012; Bruskotter and Wilson, 2013; Slagle et al., 2012, 2013). Thus, there is a need for research on how non-lethal management tools like LGDs do or do not affect attitudes towards large carnivores that is robust enough to draw on existing theories about tolerance.

We set out to measure experience with LGDs and perceptions about their effectiveness to determine if they are positively correlated with attitudes towards large carnivores. Our target populations was individuals in pastoralist communities of the Northern Rocky Mountains who would be familiar with LGD use and livestock depredation from large carnivores. While reducing depredations has generally been the focus of LGD research, the human dimensions of LGD use are also important in predicting the adoption of best management practices for LGDs, and whether or not management tools can influence acceptance of large, wild carnivores. To the extent that perceptions of LGDs are correlated with tolerance for wolves and grizzly bears, LGDs may play an important role in conservation of large carnivores. To test the hypothesis that positive attitudes towards LGDs among pastoralists predict more positive attitudes about wolves and grizzly bears, we developed a survey to gauge participants' attitudes towards all three. We modeled survey questions loosely around a Hazard-Acceptance model for tolerance of large carnivores (Bruskotter and Wilson, 2013; Slagle, 2016). The HazardAcceptance model assumes that attitudes towards wildlife are influenced by perceptions of risk and benefit associated with a species, and that those perceived risks and benefits are determined by whether a person feels they can control threats from that species, whether they trust management agencies, and their emotional reaction to the species (Bruskotter and Wilson, 2013; Slagle, 2016). However, we centered our analysis on determining how experience with and attitudes towards LGDs correlate with general attitudes towards large carnivores. Rather than strictly defining attitude towards wolves and grizzly bears, we used factor analysis to identify underlying metrics of attitudes based on grouping responses to our survey, and then used a series of questions related to LGDs to model those underlying composite metrics in a linear regression framework. While the results may not directly address whether LGDs temper pastoralists' acceptance of risks imposed by large carnivores, our findings provide generalizable lessons on how the use of non-lethal management tools and the belief in their efficacy (broadly defined) relates to general attitudes towards large carnivores.

\section{Methods}

Survey methods. We developed a 113-question survey, loosely based around a Hazard-Acceptance framework of human tolerance for wildlife (Bruskotter and Wilson, 2013; Slagle, 2016), and designed to compare respondents' attitudes towards LGDs, wolves, and grizzly bears. Some questions were adapted from other surveys of large carnivores that also employed a HazardAcceptance model of tolerance (Zajac et al., 2012; Slagle et al., 2012). The initial portion of the survey consisted of questions related to participants' experience with livestock and LGDs and was designed to help correlate attitudes with experience and exposure to livestock (sheep and cattle), LGDs, wolves, grizzly bears, and other common livestock predators. Respondents were also asked to answer demographic questions at the end of the survey. The majority of the survey questions gauged attitudes and perceptions and consisted of three sections concerning wolves, 
grizzly bears, and LGDs, respectively. Questions in the wolf and grizzly bear sections were designed to assess attitudes towards each species relative to tolerance. Questions in the LGD section were designed to assess attitudes towards LGDs specific to their usefulness. Two questions asked participants to evaluate the size of the wolf and grizzly bear populations in their state on a 3-point Likert scale (i.e., too small, appropriate, too large; Likert, 1932). All other questions in these three sections asked participants to rank their level of concurrence with a statement on a 5-point Likert scale (i.e., strongly disagree, somewhat disagree, neither agree or disagree, somewhat agree, strongly agree). The wolf and grizzly bear sections consisted of 33 nearly identical questions with only the name of the subject animal changed. The only exception was question 24, which in the wolf section asked about the appropriateness of reintroduction of wolves, and in the grizzly bear section asked about the appropriateness of continued Federal management. The LGD section consisted of 22 questions. The full survey document is available as supplementary material.

The survey was pre-tested by university graduate students to examine question clarity, subject relevance, general flow, and approximate completion time (Dillman et al., 2014). It was translated into Spanish with help from a bilingual technician and proofread by two native speakers for clarity. The Institutional Review Board for the protection of human participants at Utah State University approved the survey for distribution (Protocol \#6001). The survey was formatted for distribution as part of a printed packet that could be distributed by mail or in-person and returned anonymously via an included pre-paid return envelope. No compensation was offered for participation in the study.

Our primary focus was to survey individuals in pastoralist communities of the Northern Rocky Mountains who would be familiar with LGD use and livestock depredation from large carnivores. However, as a pseudo-control on exposure to wolves and grizzly bears while grazing livestock we also solicited responses from individuals in pastoralist communities outside of wolf and grizzly bear habitat. The survey was initially distributed to sheep producers in Idaho, Montana, Oregon, Wyoming, and Washington with whom the authors had been collaborating on a separate study of LGD effectiveness (Kinka and Young, 2018, 2019). We invited approximately 20 livestock operators, their spouses, and their employees to consider participating in the survey. Then, through a snowball sampling methodology, we asked these rancher collaborators and other collaborators with USDA Wildlife Services to solicit interest in the survey amongst their community. Surveys were also distributed at livestock association meetings, non-lethal management workshops conducted by the USDA's Wildlife Services, and at the conference of the Western Section of the Wildlife Society's annual conference in Reno, NV, USA. In total, the survey was disseminated to 234 individuals between 2014 and 2017. The survey response rate was calculated as the number of completed surveys divided by the initial number of surveys disseminated. To minimize non-response bias amongst our collaborators we continually reminded them in person to complete and return the survey, if they had not already done so. In addition, we sent multiple, mixed-media reminders to our collaborators.

Statistical analyses. Because of our small sample, we chose to examine only a subset of the questions in the wolf, grizzly bear, and LGD sections of the survey deemed most relevant to the current investigation of attitudes towards wolves, grizzly bears, and LGDs (Tables 1-3). We analyzed these subsets of the wolf, grizzly bear, and LGD sections of the survey using exploratory maximum-likelihood factor analysis. We used parallel analysis to calculate the number of interpretable factors that should be extracted. Varimax rotation, which is used to align factors so that there are a small number of variables highly loaded on each factor, was used to identify how the survey questions in each section grouped based on participants' responses. That is, only questions with loadings $\geq|0.500|$ were selected for use as components of a composite measure of attitudes towards wolves and grizzly bears in our linear modeling exercise. We used Cronbach's

Table 1 The subset of survey questions concerning wolves deemed, a priori, most relevant to this analysis

\begin{tabular}{|c|c|c|c|c|c|c|}
\hline Wolf questions & Mean & SD & $n$ & Factor 1 & Factor 2 & Factor 3 \\
\hline W1. Wolves reduce the amount of game available to hunters. & 1.10 & 1.33 & 50 & 0.92 & & \\
\hline $\begin{array}{l}\text { W2. Wolves have a negative impact on the populations of } \\
\text { their prey. }\end{array}$ & 0.80 & 1.31 & 49 & 0.77 & & \\
\hline W3. The size of the current wolf population in this state is... & 0.57 & 0.58 & 47 & 0.70 & & \\
\hline W4. Wolves are part of the natural heritage of this state. & -0.27 & 1.30 & 49 & 0.67 & & \\
\hline W5. Wolves contribute to a healthy ecosystem. & -0.30 & 1.40 & 48 & 0.66 & 0.34 & 0.33 \\
\hline W6. Wolves are putting livestock owners out of business. & 0.52 & 1.49 & 48 & 0.61 & 0.57 & \\
\hline W7. I enjoy seeing wolves. & -0.73 & 1.34 & 49 & 0.56 & & \\
\hline $\begin{array}{l}\text { W8. Livestock can not be successfully grazed in areas with } \\
\text { wolves. }\end{array}$ & 0.29 & 1.40 & 49 & & 0.72 & \\
\hline W9. Wolves cause livestock owners to lose money. & 1.41 & 0.96 & 49 & 0.36 & 0.68 & \\
\hline W10. Wolves will always be a problem for livestock owners. & 1.33 & 0.93 & 48 & & 0.61 & 0.34 \\
\hline W11. How would you describe your feelings about wolves? & -0.98 & 1.21 & 48 & 0.50 & 0.58 & 0.36 \\
\hline W12. Wolves generate tourism revenue for this state. & -1.22 & 1.56 & 49 & 0.35 & & 0.92 \\
\hline W13. Wolves generate hunting revenue for this state. & -1.02 & 1.22 & 49 & & & 0.73 \\
\hline W14. I am afraid of wolves. & -0.26 & 1.42 & 47 & & 0.45 & \\
\hline W15. Wolves are a threat to human safety. & 0.13 & 1.21 & 48 & & 0.41 & 0.39 \\
\hline Sums of squared loadings & & & & 4.14 & 2.69 & 2.02 \\
\hline Proportion of variance explained & & & & 0.28 & 0.18 & 0.14 \\
\hline Cumulative variance explained & & & & 0.28 & 0.46 & 0.59 \\
\hline Cronbach's $\alpha$ & & & & 0.87 & 0.82 & 0.80 \\
\hline
\end{tabular}

Respondents ranked their level of concurrence with each of the following statements along a 5-point Likert scale (i.e., strongly negative, somewhat negative, neither positive nor negative, somewhat positive, strongly positive) except for the second statement which was ranked on a 3-point Likert scale (i.e., too small, appropriate, too large). Mean response, standard deviation (SD), and number of respondents $(n)$ are shown for each question, along with factor loadings determined from maximum-likelihood exploratory factor analysis. The responses to question in italics were reverse coded before factor analysis. Loadings $<|0.300|$ are hidden for clarity. Cronbach's $\alpha$ is shown for each factor, which includes only those questions which mapped most strongly onto the factor (in bold). Questions with factor loadings $<|0.500|$ were not used to calculate Cronbach's $\alpha$. Note that question W6 loaded approximately equally onto both factors 
Table 2 The subset of survey questions concerning grizzly bears deemed, a priori, most relevant to this analysis

\begin{tabular}{|c|c|c|c|c|c|}
\hline Grizzly bear questions & Mean & SD & $\boldsymbol{n}$ & Factor 1 & Factor 2 \\
\hline G5. Grizzly bears contribute to a healthy ecosystem. & 0.08 & 1.29 & 39 & 0.82 & \\
\hline G11. How would you describe your feelings about grizzly bears? & -0.27 & 1.00 & 41 & 0.81 & 0.40 \\
\hline G4. Grizzly bears are part of the natural heritage of this state. & 0.05 & 1.28 & 40 & 0.73 & \\
\hline G7. I enjoy seeing grizzly bears. & 0.43 & 1.20 & 40 & 0.62 & 0.31 \\
\hline G1. Grizzly bears reduce the amount of game available to hunters. & 0.33 & 1.38 & 40 & 0.62 & 0.42 \\
\hline G3. The size of the current grizzly bear population in this state is... & 0.26 & 0.55 & 39 & 0.59 & \\
\hline G6. Grizzly bears are putting livestock owners out of business. & 0.21 & 1.55 & 42 & & 0.94 \\
\hline G9. Grizzly bears cause livestock owners to lose money. & 1.04 & 1.18 & 42 & & 0.83 \\
\hline G8. Livestock cannot be successfully grazed in areas with grizzly bears. & 0.12 & 1.53 & 42 & & 0.76 \\
\hline G2. Grizzly bears have a negative impact on the populations of their prey. & 0.35 & 1.31 & 40 & 0.55 & 0.59 \\
\hline G15. Grizzly bears a threat to human safety. & 0.80 & 1.11 & 40 & 0.32 & 0.44 \\
\hline G12. Grizzly bears generate tourism revenue for this state. & -0.75 & 1.24 & 40 & 0.34 & -0.34 \\
\hline G13. Grizzly bears generate hunting revenue for this state. & -0.73 & 1.30 & 40 & & 0.33 \\
\hline G14. I am afraid of grizzly bears. & 0.83 & 1.22 & 40 & & \\
\hline Sums of squared loadings & & & & 3.65 & 4.09 \\
\hline Proportion of variance explained & & & & 0.24 & 0.27 \\
\hline Cumulative variance explained & & & & 0.52 & 0.27 \\
\hline
\end{tabular}

Respondents ranked their level of concurrence with each of the following statements along a 5-point Likert scale (i.e., strongly negative, somewhat negative, neither positive nor negative, somewhat positive, strongly positive) except for the second statement which was ranked on a 3-point Likert scale (i.e., too small, appropriate, too large). Mean response, standard deviation (SD), and number of respondents $(n)$ are shown for each question, along with factor loadings determined from maximum-likelihood exploratory factor analysis. The responses to question in italics were reverse coded before factor analysis. Loadings $<|0.300|$ are hidden for clarity. Cronbach's $\alpha$ is shown for each factor, which includes only those questions which mapped most strongly onto the factor (in bold). Questions with factor loadings $<|0.500|$ were not used to calculate Cronbach's $\alpha$. Note that question G2 loaded approximately equally onto both factors

Table 3 Survey questions considered as predictor variables in linear modeling

\section{Question text}

E1. How many years have you used livestock guardian dogs to protect livestock?a

E2. How often do you encounter wolves while grazing livestock?b

E3. How often do you encounter grizzly bears while grazing livestock?b

E4. How often have you lost livestock to wolves while grazing livestock? ${ }^{b}$

E5. How often have you lost livestock to grizzly bears while grazing livestock?b

L1. Livestock guardian dogs are a necessary tool for protecting sheep from wolves ${ }^{c}$

L2. Livestock guardian dogs are a necessary tool for protecting sheep from grizzly bears ${ }^{c}$

L3. Using livestock guardian dogs is a good idea for most livestock owners ${ }^{\mathrm{c}}$

4. Using livestock guardian dogs with my own livestock is a good ideac

L5. Livestock guardian dogs are a useful tool for protecting sheep from grizzly bears ${ }^{c}$

L6. Livestock guardian dogs are a useful tool for protecting sheep from wolves

L7. Livestock guardian dogs are a vital part of any livestock operation ${ }^{c}$

L8. The costs associated with keeping livestock guardian dogs are worth the economic benefits they providec

L9. Livestock guardian dogs do more harm than goodc

L10. Livestock guardian dogs are a threat to human safety

L11. Livestock guardian dogs prevent livestock being stolen by other peoplec

L12. Livestock guardian dogs reduce livestock owners' reliance on government agencies to manage and control predators ${ }^{c}$

L13. Livestock guardian dogs reduce the need for lethal removal of predators ${ }^{c}$

L14. Livestock guardian dogs prevent the spread of disease between wild animals and livestock

Sums of squared loadings

Proportion of variance explained

Cumulative variance explained

Cronbach's $\alpha$

\begin{tabular}{lllll} 
Mode/mean & SD & n & Factor 1 & Factor 2 \\
\hline 10 or more & & 48 & & \\
Never & & 46 & & \\
Never & & 47 & & \\
Never & & 46 & & \\
Never & & 45 & & \\
1.06 & 1.23 & 48 & $\mathbf{0 . 9 0}$ & 0.33 \\
0.77 & 1.26 & 44 & $\mathbf{0 . 8 4}$ & 0.40 \\
1.23 & 1.03 & 47 & $\mathbf{0 . 8 2}$ & \\
1.62 & & 47 & $\mathbf{0 . 8 2}$ & \\
0.94 & 1.16 & 49 & $\mathbf{0 . 7 0}$ & 0.53 \\
1.78 & 0.55 & 50 & $\mathbf{0 . 6 6}$ & 0.54 \\
1.32 & 1.08 & 50 & $\mathbf{0 . 6 4}$ & -0.45 \\
1.49 & 0.69 & 47 & $\mathbf{0 . 5 7}$ & \\
-1.65 & 0.78 & 49 & & $-\mathbf{0 . 6 0}$ \\
-1.47 & 0.81 & 50 & & -0.39 \\
0.65 & 1.11 & 49 & & 0.39 \\
0.78 & 1.25 & 46 & & \\
0.36 & 1.52 & 47 & & \\
0.58 & 1.11 & 48 & & \\
& & & 4.60 & 1.80 \\
& & & 0.33 & 0.13 \\
& & & 0.33 & 0.46 \\
& & & 0.91 & na \\
\hline
\end{tabular}

Mean response is shown for questions with continuous response options, and mode is shown for categorical responses. Standard deviations (SD) are shown for questions with continuous response options, along with factor loadings determined from maximum-likelihood exploratory factor analysis. Number of respondents $(n)$ is shown for each question. The responses to question in italics were reverse coded before factor analysis. Loadings $<|0.300|$ are hidden for clarity. Cronbach's $\alpha$ is shown for each factor, which includes only those questions which mapped most strongly onto the factor (in bold). Questions with factor loadings $<|0.500|$ were not used to calculate Cronbach's $\alpha$

aNone, less than 1, 1-5, 6-10, 10 or more

bNever, at least once a year, at least once a month, at least once a week, at least once a day

cStrongly disagree, somewhat disagree, neither or agree or disagree, somewhat agree, strongly agree

$\alpha$ coefficient to assess the internal reliability of these composite measures. Responses to the selected questions were reverse coded if necessary, averaged within each factor and carried forward as dependent variables in linear regression analyses. Factor analysis of questions in the LGD section of the survey were used to inform our choice of predictor variables in subsequent linear regression modeling. Candidate predictor variables in the linear regression models were chosen based upon relevance to the question of whether or not attitude towards LGDs predicts attitudes towards wolves or grizzly bears and how questions clustered during factor analysis. To avoid collinearity in our models, we selected only LGD questions with distinct factor loadings, to ensure that each question addressed a specific component of attitudes towards LGDs. Unlike for wolves and grizzly bears, instead of using factor analysis to generate a composite metric for attitudes towards LGDs, we chose the single LGD question with the highest loading on each factor (Table 3 ) as a predictor variable in linear regression. Thus, LGD questions 1 or 2, 9, 12-14 (Table 3) were used as predictor variables in all linear modeling exercises. In addition, we identified five questions from the experience section of the survey we believed might influence participants' attitudes towards wolves or grizzly bears (Table 3). For LGD and experience questions relating specifically to either wolves of grizzly bears, only the question relating to the same species as the dependent 
variable was included in the model (Tables 4-7). We considered all combinations of predictor variables to be relevant before running analyses, and therefore included all combinations of predictors as candidate models. Analyses were performed using the 'psych' package (Revelle, 2017) and 'lm' function available in $R$ version 3.3.2 ( $R$ Core Team, 2016). Model selection for fixed effects was conducted using Akaike's Information Criterion for small samples.

\section{Results}

Survey. We distributed 234 surveys and 50 were returned for a response rate of $21.4 \%$. Of that total, 45 participants responded using the English-language survey (out of 203 distributed) and 5 participants responded using the Spanish-language (out of 31 distributed). Thirty-three of the respondents reported as male and 16 female; one did not respond to the question. Most respondents $(n=16)$ reported as being between 56 and 65 years of age. The typical respondent had at least a bachelor's degree $(n=20)$ and earned between $\$ 50,000$ and $\$ 99,999$ per year $(n=21)$, of which $75-100 \%$ came from livestock $(n=14)$. Of the 46 participants who responded to the wolf encounter question, $35 \%$ of respondents $(n=16)$ reported encountering wolves while grazing livestock at least once a year, with an additional 13\% $(n=6)$ encountering wolves at least once a month. The rest (52\%) reported never encountering wolves. Losing livestock to wolves was less common than encountering them, with $21 \%(n=9)$ of the 43 participants who responded to the wolf depredation question reporting losing livestock to wolves at least once a year, and an additional $9 \%(n=4)$ reporting losing livestock to wolves at least once a month. The rest (70\%) reported never losing livestock to wolves.

Experience with grizzly bears was less common than for wolves. Four percent of respondents $(n=2)$ reported encountering grizzly bears while grazing livestock at least once a year, with an additional $4 \%(n=2)$ encountering grizzly bears at least once a month. The rest (92\%) reported never encountering grizzly bears. Four percent of respondents $(n=2)$ reporting losing livestock to grizzly bears at least once a year, and an additional $2 \%(n=1)$ reporting losing livestock to grizzly bears at least once a month. The rest (94\%) reported never losing livestock to grizzly bears.

Factor analysis. Results of parallel analyses used to calculate the number of interpretable factors that should be extracted from each question set indicated that three factors could be identified in the wolf question set, and two each in the grizzly bear and LGD question set. Although questions were nearly identical for wolves and grizzly bears, respondents' answers clustered slightly differently by species in factor analysis (Tables 1 and 2). For wolves, we identified three distinct factors (Table 1). Seven questions loaded strongly onto the first factor identified for wolves (i.e., $\geq|0.500|$ ), four on the second, and two on the third. With the exception of wolf question six and perhaps seven (W6 and W7, Table 1) all of the wolf questions with strong loadings on the first factor reference wolves in the wilderness, including how they interact with hunters $(\mu=-0.61, \mathrm{SD}=0.96, \alpha=0.87$; Table 1$)$. The second wolf factor is comprised largely of questions which reference how wolves interact with livestock, ranching, and ranchers $(\mu=-1.01$, $\mathrm{SD}=0.93, \alpha=0.82$; Table 1 ). The third wolf factor was comprised of two questions that reference revenue generated from wolves $(\alpha=0.82$; Table 1$)$. We used raw averages of rankings in wolf factors one and two as dependent variables in linear modeling.

Factor loadings for grizzly bear questions had two salient factors emerge (Table 2). Six questions loaded strongly onto the first factor (i.e., $\geq|0.500|$ ), all of which reference grizzly bears in the wilderness, including how they interact with hunters $(\mu=$ $-0.18, \mathrm{SD}=0.89, \alpha=0.84$; Table 2 ). Five other grizzly bear questions loaded heavily onto a second factor, all of which reference how grizzly bears interact with livestock, ranching, and ranchers, except grizzly bear question 2 (G2, Table 2) which loaded nearly equally on both factors and seems to be more logically associated with the first factor $(\mu=-0.58, \mathrm{SD}=1.20$, $\alpha=0.90$; Table 2). We used raw averages of scores in grizzly bear factors one and two as dependent variables in linear modeling.

Factor loadings for LGD questions had two salient factors emerge (Table 3). Eight questions loaded onto the first factor (i.e., $\geq|0.500|$ ), all of which have to do with LGDs' usefulness to pastoralists $(\alpha=0.91)$. Only one question loaded onto the second LGD factor at a significant threshold $(\geq|0.500|)$, which asked participants to weigh whether they thought LGDs did more harm than good. Three other LGD questions did not load significantly on to either LGD factor (L12-L14; Table 3), nor are they related to one another $(\alpha=0.12)$.

Linear regression models. For the model set related to the first wolf factor, both top models (i.e., $\Delta \mathrm{AICc} \leq 2.0$ ) indicate that level of concurrence with LGD questions 13 and 14 (L13 and L14, Table 3) is predictive of more positive attitudes toward wolves (Table 4). That is, the more respondents agreed that LGDs reduce the need for lethal management $(p<0.01)$ and prevented the spread of disease $(p<0.05)$, the more positive their opinion of wolves. For the model set related to the second wolf factor, all four top models (i.e., $\Delta \mathrm{AICc} \leq 2.0$ ) indicate that level of concurrence with LGD questions 9 and 13 (L9 and L13, Table 3) is predictive of more positive attitudes toward wolves (Table 5). That is, the more respondents agreed that LGDs do more harm

Table 4 Model results for all linear models of attitudes towards wolves with $\Delta$ AICc $\leq 2.00(n=35)$

Top Wolf Attitude Models, Factor 1-"wolves in the wild" Global Model: Im(Wolf Factor $1 \sim$ E1 + E2 + E4 $+\mathbf{L 1}+\mathbf{L 9}+\mathbf{L 1 2}+\mathbf{L 1 3}+\mathbf{L 1 4})$

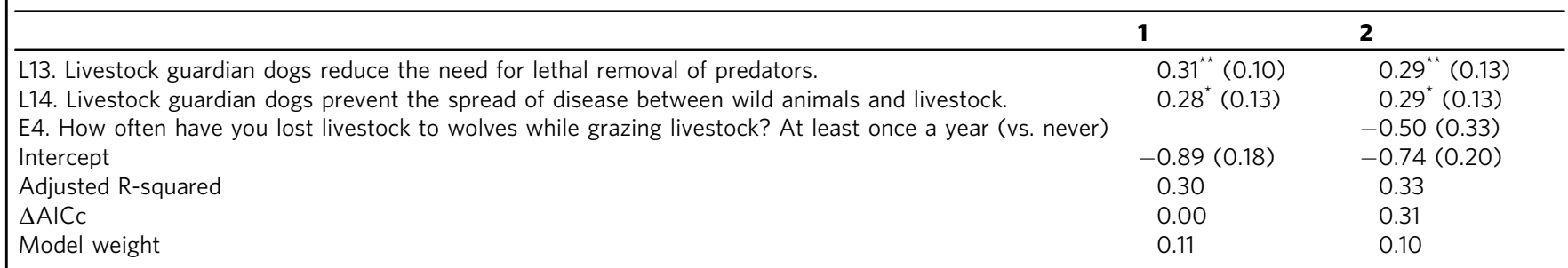

Results are shown as coefficient values with standard error shown in parentheses below. The dependent variable in all models was a composite measure of general attitude for wolves, composed of an average of scores for six survey questions about wolves that loaded on to a single factor with a loading of $|0.500|$ or more. The factor upon which all questions comprising the dependent variable loaded is best described as "wolves in the wild"

${ }^{\star} p<0.05,{ }^{\star \star} p<0.01$ 
Table 5 Model results for all linear models of attitudes towards wolves with $\Delta$ AICc $\leq 2.00(n=36)$

Top Wolf Attitude Models, Factor 2-"wolves and livestock" Global Model: Im(Wolf Factor 2 E1 + E2 + E4 + L1 + L9 + L12 + L13 + L14)

\begin{tabular}{|c|c|c|c|c|}
\hline & 1 & 2 & 3 & 4 \\
\hline L9. Livestock guardian dogs do more harm than good. & $0.50^{\star}(0.22)$ & $0.57^{\star}(0.23)$ & $0.47^{\star}(0.22)$ & $0.52^{\star}(0.22)$ \\
\hline $\begin{array}{l}\text { L13. Livestock guardian dogs reduce the need for lethal removal of } \\
\text { predators. }\end{array}$ & $0.35^{\star \star \star}(0.09)$ & $0.33^{\star \star \star}(0.07)$ & $0.33^{\star \star \star}(0.09)$ & $0.33^{\star \star \star}(0.33)$ \\
\hline
\end{tabular}

At least once a year (vs. never)

L14. Livestock guardian dogs prevent the spread of disease between wild

$0.12(0.12)$

animals and livestock.

L1. Livestock guardian dogs are a necessary tool for protecting sheep

from wolves.

Intercept

Adjusted R-squared

$\triangle \mathrm{AICc}$

Model weight

\begin{tabular}{llcc} 
& $0.12(0.12)$ & \\
& & & $0.09(0.11)$ \\
$-0.19(0.41)$ & $0.03(0.45)$ & $-0.32(0.43)$ & $-0.22(0.41)$ \\
0.38 & 0.38 & 0.38 & 0.37 \\
0.00 & 1.28 & 1.45 & 1.93 \\
0.13 & 0.07 & 0.06 & 0.05 \\
\hline
\end{tabular}

Results are shown as coefficient values with standard error shown in parentheses. The dependent variable in all models was a composite measure of general attitude for wolves, composed of an average of scores for six survey questions about wolves that loaded on to a single factor with a loading of $|0.500|$ or more. The factor upon which all questions comprising the dependent variable loaded is best described as "wolves and livestock"

${ }^{\star} p<0.05,{ }^{\star \star *} p<0.001$

Table 6 Model results for all linear models of tolerance for grizzly bears with $\Delta$ AICc $\leq 2.00(n=32)$

Top Grizzly Bear Attitude Models, Factor 1-“grizzly bears in the wild" Global Model: Im(Grizzly Bear Factor $1 \sim$ E1 + E3 + E5 + L2 + L9 + L12 + L13 + L14)

\begin{tabular}{|c|c|c|c|c|c|c|c|}
\hline & 1 & 2 & 3 & 4 & 5 & 6 & 7 \\
\hline $\begin{array}{l}\text { L12. Livestock guardian dogs reduce } \\
\text { livestock owners' reliance on } \\
\text { government agencies to manage and } \\
\text { control predators. }\end{array}$ & $0.23(0.13)$ & $0.26^{*}(0.13)$ & & $0.19(0.13)$ & & $0.22(0.13)$ & \\
\hline $\begin{array}{l}\text { L14. Livestock guardian dogs prevent the } \\
\text { spread of disease between wild animals } \\
\text { and livestock. }\end{array}$ & & $0.21(0.14)$ & & & & $0.19(0.14)$ & $0.17(0.15)$ \\
\hline Adjusted R-squared & 0.07 & 0.11 & 0.05 & 0.09 & na & 0.11 & 0.01 \\
\hline$\triangle \mathrm{AICc}$ & 0.00 & 0.19 & 0.66 & 0.93 & 0.94 & 1.75 & 2.00 \\
\hline Model weight & 0.07 & 0.06 & 0.05 & 0.04 & 0.04 & 0.03 & 0.02 \\
\hline
\end{tabular}

than good $(p<0.05)$ and reduce the need for lethal management $(p<0.001)$, the more positive their opinion of wolves.

For grizzly bear factor one, we identified seven top models $(\triangle \mathrm{AICc} \leq 2.0)$, but only LGD question $12(\mathrm{~L} 12$, Table 3$)$ was a significant predictor of attitudes towards grizzly bears $(p<0.05)$, and only in the second highest ranking model (Table 6). For grizzly bear factor two, nine top models were identified (Table 7). However, only experience question 1 (E1, Table 3) was a significant predictor of attitudes towards grizzly bears. Consistently across all nine top models, respondents with up to 10 years' experience using LGDs had more negative attitudes towards grizzly bears on this metric $(p<0.01)$ and respondents with more than 10 years' experience using LGDs had the most negative attitudes towards grizzly bears $(p<0.001$; Table 7$)$.

\section{Discussion}

While LGDs may effectively deter small livestock predators (Gehring et al., 2010), experience using LGDs alone does not temper pastoralists' attitudes about large predators of livestock.
General attitudes about LGDs (i.e., L7, Table 3) and opinions about their usefulness (i.e., L5 and L6, Table 3) were largely positive amongst our respondents, but the metric we chose to represent general attitude towards LGDs (i.e., L1 or L2) did not predict attitudes towards large carnivores (Tables 4-7). The LGD perceptions which significantly predicted attitudes towards wolves concerned lethal removal of predators (i.e., L13, Tables 4 and 5), spread of disease (i.e., L14, Tables 4 and 5), and overall benefits (i.e., L9, Table 5). For grizzly bears, the only LGD question which significantly predicted attitude referenced reliance on government agencies (i.e., L12, Table 6), and only in the second highest ranked model.

While these results may suggest LGDs have some ability to increase tolerance for wolves and grizzly bears, the causal order of these effects is difficult to discern. It may be that a more positive attitude for wolves and grizzly bears to begin with predicts a more optimistic attitudes about LGDs and their capacity to reduce human-wildlife conflict and, more specifically, reduce the need for lethal management of large carnivores. The strongest 
Table 7 Model results for all linear models of tolerance for grizzly bears with $\Delta$ AlCc $\leq 2.00(n=36)$

Top Grizzly Bear Attitude Models, Factor 2-“grizzly bears and livestock" Global Model: Im(Grizzly Bear Factor $2 \sim$ E1 + E3 + E5 + L2 + L9 + L12 + L13 + L14)

\begin{tabular}{|c|c|c|c|c|c|c|c|c|c|}
\hline & 1 & 2 & 3 & 4 & 5 & 6 & 7 & 8 & 9 \\
\hline \multicolumn{10}{|c|}{ E1. How many years have you used livestock guardian dogs to protect livestock? } \\
\hline $\begin{array}{l}0-10 \text { years } \\
\text { (vs. never) }\end{array}$ & $-2.15^{k \star}(0.61)$ & $-1.99^{* x}(0.63)$ & $-2.13^{* \star}(0.63)$ & $-1.98^{\star \star}(0.62)$ & $-1.80^{\star \star}(0.62)$ & $-1.85^{\star \star}(0.64)$ & $-1.83^{\star \star}(0.65)$ & $-1.99^{\star \star}(0.62)$ & $-2.04^{\star \star}(0.63)$ \\
\hline $\begin{array}{l}10+\text { years } \\
\text { (vs. never) }\end{array}$ & $-2.52^{\star \star \star}(0.57)$ & $-2.17^{\star \star \star}(0.57)$ & $-2.21^{\star \star \star}(0.56)$ & $-2.42^{\star \star \star}(0.58)$ & $-2.40^{\star \star \star}(0.58)$ & $-2.13^{\star \star \star}(0.57)$ & $-2.14^{\star \star \star}(0.57)$ & $-2.50^{\star \star \star}(0.57)$ & $-2.12^{\star \star \star}(0.57)$ \\
\hline $\begin{array}{l}\text { L9. Livestock } \\
\text { guardian dogs do } \\
\text { more harm } \\
\text { than good. }\end{array}$ & $-0.45(0.25)$ & & & $-0.37(0.26)$ & $-0.43(0.26)$ & & & $-0.48(0.25)$ & \\
\hline $\begin{array}{l}\text { L14. Livestock } \\
\text { guardian dogs }\end{array}$ & $0.28(0.16)$ & & $0.23(0.16)$ & & & & & $0.25(0.16)$ & \\
\hline
\end{tabular}

spread of disease

between wild

animals and

livestock.

L12. Livestock

guardian dogs

reduce livestock

owners' reliance

on government

agencies to

manage and

control predators.

E5. How often

have you lost

livestock to

grizzly bears

while grazing

livestock? At

least once a year

(vs. never)

L13. Livestock

guardian dogs

reduce the need

for lethal removal

of predators.

Adjusted R-

squared

$\triangle \mathrm{AICC}$

Model weight

$0.67(0.60)$

0.33

0.00
0.07

0.00
0.07
$1.38(0.52)$

0.27

0.18

0.06
$1.26(0.52)$

0.29

0.60

0.05
$-0.21(0.15)$

$-0.17(0.15)$

$-0.16(0.15)$

Results are shown as coefficient values with standard error shown in parentheses. The dependent variable in all models was a composite measure of general attitude for wolves, composed of an average of scores for six survey questions about wolves that loaded on to a single factor with a loading of $|0.500|$ or more. The factor upon which all questions comprising the dependent variable loaded is best described as "grizzly bears and livestock"

${ }^{\star \star} p<0.01,{ }^{\star \star \star} p<0.001$

predictor of both composite metrics of attitudes towards wolves was level of concurrence with the statement "livestock guardian dogs reduce the need for lethal removal of predators." Interestingly, this statement has as much to do with LGDs as respondents' general feelings towards lethal management. That is, a respondent might feel that, while LGDs are a very effective tool (which was the general pattern in our data), their purpose is not to replace or reduce the need for lethal management, nor is that a relevant measure of LGD efficacy. So, to suggest that believing LGDs reduce the need for lethal management of wolves is predictive of more positive attitudes towards wolves may be the tail wagging the dog (although this should be tested explicitly).

Surprisingly, using LGDs for any length of time predicted more negative attitudes towards grizzly bears. Using LGDs for up to 10 years significantly predicted more negative views of grizzly bears (compared to no use of LGDs), and more than 10 years' experience with LGDs predicted even more negative attitudes towards grizzly bears. We did not find the same effect for wolves. Viewed as a proxy of experience dealing with livestock predators, length of time using LGDs may corroborate other findings that attitudes towards predators deteriorate after prolonged exposure to them (Dressel et al., 2014), even though length of exposure is also correlated with self-reported acceptance and interest in coexistence (Young et al., 2015). Encounter rate by pastoralists (i.e., how often a rancher or shepherd encounters wolves) has been shown to be the strongest predictor of perceived risk from wolves (Suryawanshi et al., 2013), but we did not find it to be a significant predictor of attitudes toward wolves or grizzly bears in this study. Nor did actual experience losing livestock to wolves or grizzly bears significantly predict participants' attitudes towards those carnivores. That actual experience losing livestock to large carnivores did not significantly predicted a more negative attitudes is somewhat surprising. We would assume that pastoralists' who regularly lose livestock to large carnivores would view them more negatively (Suryawanshi et al., 2013, 2014; Dressel et al., 2014; Miller et al., 2016). However, this may simply be an artifact of how rare the experience of losing livestock to wolves or grizzly bears was amongst our respondents. In fact, the majority of respondents did not have losses to these carnivores; only $6 \%$ of respondents reported losses to grizzly bears and 30\% reported losses to wolves. Populations of both wolves and grizzly bears continue to expand in this area, so more livestock depredation is likely. This evolving scenario may alter attitudes in the future.

Interestingly, despite how strongly politicized wolves have become in the Northern Rocky Mountains (relative to grizzly bears) (Wilson, 1997; Mech, 2012; Berry et al., 2016), respondents' answers to wolf and grizzly bear questions mapped onto very similar dimensions in factor analysis. With the exception of two questions (W11, Table 1; and G2; Table 2), responses for each species seemed to map clearly and consistently along at least two factors, the first strongly associated with wolves and grizzly bears in the wilderness, including how they interact with hunters (e.g., W5, Table 1; and G5, Table 2) and the second having more to do with the practicality and economics of raising livestock alongside 
large carnivores (e.g., W8, Table 1; and G8, Table 2). A third factor, relating to revenue-generation (i.e., W12 and W13, Table 1; and G12 and G13, Table 2) also emerged for wolves and may have for grizzly bears with more data, but we chose not to investigate the latent factor for wolves to maintain consistency in our analysis of the two large carnivore species and because revenue generation involves many other factors and beliefs outside this scope of this study. Respondents seemed to be able to readily differentiate their beliefs about wolves and grizzly bears as abstract components of wilderness and natural systems, and as tangible threats to pastoralism and intersecting areas of wilderness and anthropogenic utilization. While average responses to both composite metrics for wolves and grizzly bears were negative, average responses to the wolf and grizzly metric regarding livestock were both lower than for the metrics related to wild systems. While one LGD question was a significant predictor of both composite metrics of attitudes towards wolves (i.e., L13, Table 3), and the most predictive of wolf attitudes overall, the predictors of the two composite grizzly bear metrics were largely dissimilar. Thus, LGDs seem to have a similar impact on pastoralists' views of wolves (in the wild or livestock predators), while LGDs and their use are linked to attitudes towards grizzly bears in different ways depending on context.

LGDs have been shown to be effective and reduce depredations from many different carnivores, although little empirical evidence exists for wolves and grizzly bears (Gehring et al., 2010; van Bommel and Johnson, 2012; Kinka and Young, 2019). Even so, increasing tolerance for wolves and grizzly bears, especially among pastoralists, may be a task LGDs are poorly suited for. Consider, for instance, practical versus substantive threat (Kalberg, 1980). Generally more objective and easier to quantify, practical threats from wolves and grizzly bears would include livestock depredation. These threats are easily understood (Muhly and Musiani, 2009) and direct action can be taken to try and mitigate them using tools such as LGDs (Gehring et al., 2010; van Bommel and Johnson, 2012). Substantive threats, however, involve navigating a constellation of morals and ideas about how the world should be, having less to do with an individual's pragmatic interests as with their values (Kalberg, 1980). The substantive threat of wolves and grizzly bears must be thought of in terms of competing values-not the danger of the animals themselves, but what they represent. Regarded as a substantive threat, neither wolves nor grizzly bears would be expected to be viewed more favorably just because LGDs remove some of the practical threats associated with each. Indeed, the economic cost of wolf depredation to the livestock industry as a whole is marginal (Muhly and Musiani, 2009), and our respondents reported that losses to wolves and grizzly bears were uncommon. Yet negative attitudes towards wolves and grizzly bears were frequently observed. Thus, while non-lethal management tools like LGDs can be extremely useful in addressing practical threats to the livestock industry, addressing the substantive threat carnivores represent for pastoralists may require a different set of tools. It is also possible that with the use of LGDs in the US only dating back a couple decades, there has not been enough time to document the effect of LGDs on addressing the substantive threat of large carnivores. Perhaps over a longer time period a reduction in the practical threats of carnivores will change perception of the substantive threat.

While our small sample prohibited a more nuanced look at these data and limited the inference, this study is the largest on the relationship between use of LGDs and attitudes toward large carnivores to date. Despite being the largest study of its kind, the non-response rate for our survey-particularly among Spanish speakers-could have biased our results, and we urge the reader to interpret our results in the context of possible methodological limitations. We believe our results, at least within the English survey responses, are likely to be representative of the ranching community because past surveys have shown that nonresponse bias is not an issue when survey populations are fairly homogenous (Becker and Iliff, 1983; Brown et al., 1989; Connelly et al., 2003; Kreuter, 2013; Gigliotti and Fopma, 2019). Further, the majority of survey questions showed considerable dispersion around the mean considering we used a 5-point Likert Scale for most questions (see standard deviations in Tables 1-3), indicating that the survey captured a variety of attitudes and perspectives amongst respondents. Future work may seek to compare nonresponse data more directly and establish causality or directionality between attitudes towards non-lethal management tools and attitudes for contentious carnivores. In addition, future work should seek to further disentangle the substantive and practical threats of large carnivores to pastoralists, in hopes of improving coexistence on shared landscapes. Regardless, the evidence we present here does not seem to support the hypothesis that using LGDs, nor beliefs in their efficacy and usefulness, tempers attitudes towards wolves or grizzly bears.

\section{Conclusions}

We present evidence that LGD use in the US does not seem to have resulted in more positive attitudes about wolves or grizzly bears amongst pastoralists. These results suggest that pastoralists' attitudes about large carnivores are dictated by more than just the practical and economic threats they pose to the ranching industry. While a small sample prohibits a more nuanced look at these data and limits inference, this study is the largest of LGDs' relationship with attitudes towards large carnivores to date. Future work may seek to further disentangle the substantive and practical threats of large carnivores to pastoralists, in hopes of improving coexistence on shared landscapes.

\section{Data availability}

The datasets collected and analyzed during the current study are available in the Dataverse repository: https://doi.org/10.7910/ DVN/X8NZDE.

Received: 17 June 2019; Accepted: 16 September 2019; Published online: 08 October 2019

\section{References}

Andelt WF, Hopper SN (2000) Livestock guard dogs reduce predation on domestic sheep in Colorado. J Rangel Manag 53:259-267

Becker BH, Iliff TJ (1983) Nonrespondents in homogeneous groups: implication for mailed surveys. Leis Sci 5:257-267

Berger KM (2006) Carnivore-livestock conflicts: effects of subsidized predator control and economic correlates on the sheep industry. Conserv Biol 20:751-761

Bergstrom BJ (2017) Carnivore conservation: shifting the paradigm from control to coexistence. J Mammal 98:1-6

Berry MS, Nickerson NP, Metcalf EC (2016) Using spatial, economic, and ecological opinion data to inform gray wolf conservation. Wildl Soc Bull 40:554-563

Bradley EH, Robinson HS, Bangs EE, Kunkel K, Jimenez MD, Gude JA, Grimm T (2015) Effects of wolf removal on livestock depredation recurrence and wolf recovery in Montana, Idaho, and Wyoming. J Wildl Manag 79:1337-1346

Brown TL, Decker DJ, Connelly NA (1989) Response to mail surveys on resourcebased recreation topics: a behavioral model and an empirical analysis. Leis Sci 11:99-110

Bruskotter JT, Wilson RS (2013) Determining where the wild things will be: using psychological theory to find tolerance for large carnivores. Conserv Lett 7:158-165

Connelly NA, Brown TL, Decker DJ (2003) Factors affecting response rates to natural resource-focused mail surveys: empirical evidence of declining rates over time. Soc Nat Resour 16:541-549

Coppinger R, Coppinger L (2002) Dogs: a new understanding of canine origin, behavior and evolution. University of Chicago Press, Chicago 
Dillman DA, Smyth JD, Christian LM (2014) Internet, phone, mail, and mixed-mode surveys: the tailored design method, 4th edn. John Wiley \& Sons, Inc, Hoboken

Dressel S, Sandström C, Ericsson G (2014) A meta-analysis of studies on attitudes toward bears and wolves across Europe 1976-2012. Conserv Biol 29:565-574

Eklund A, López-Bao JV, Tourani M, Chapron G, Frank J (2017) Limited evidence on the effectiveness of interventions to reduce livestock predation by large carnivores. Sci Rep 7:127-129

Feldman JW (2007) Public opinion, the Leopold Report, and the reform of federal predator control policy. Hum-Wildl Confl 1:112-124

Fishbein M, Ajzen I (2009) Predicting and changing behavior: the reasoned action approach. Psychology Press, Taylor \& Francis Group, New York

Fritts SH, Stephenson RO, Hayes RD and Boitani L (2003) Wolves and humans. In: Mech LD, Boitani L (eds) Wolves: behavior, ecology and conservation. University of Chicago Press, Chicago, pp. 289-340.

Gehring TM, VerCauteren KC, Landry JM (2010) Livestock protection dogs in the 21st century: is an ancient tool relevant to modern conservation challenges? BioScience 60:299-308

Gigliotti LM, Fopma SJ (2019) Low survey response! Can I still use the data? Hum Dimens Wildl 24:71-79

Hansen I, Staaland T, Ringsø A (2002) Patrolling with livestock guard dogs: a potential method to reduce predation on sheep. Acta Agric Scand. Sect AAnim. Sci. 52:43-48

Kalberg S (1980) Max Weber's types of rationality: cornerstones for the analysis of rationalization processes in history. Am J Sociol 85:1145-1179

Kinka D, Young JK (2018) A livestock guardian dog by any other name: similar response to wolves across livestock guardian dog breeds. Rangel Ecol Manag 71:509-517

Kinka D, Young JK (in press) Evaluating domestic sheep survival with different breeds of livestock guardian dogs. Rangeland Ecol Manag

Knopff AA, Knopff KH, St Clair CC (2016) Tolerance for cougars diminished by high perception of risk. Environ Soc 21:33

Kreuter F (2013) Facing the nonresponse challenge. Ann Am Acad Polit Soc Sci 645:23-35

Likert R (1932) A technique for the measurement of attitudes. Arch Psychol 22:55

Marker LL, Dickman AJ, Macdonald DW (2005) Perceived effectiveness of livestock-guarding dogs placed on Namibian farms. Rangel Ecol Manag 58:329-336

Marker L, Dickman A, Schumann M (2005) Using livestock guarding dogs as a conflict resolution strategy on Namibian farms. Damage Prev News 8:28-32

Mech LD (2012) Is science in danger of sanctifying the wolf? Biol Conserv 150:143-149

Miller JR, Jhala YV, Schmitz OJ (2016) Human perceptions mirror realities of carnivore attack risk for livestock: implications for mitigating humancarnivore conflict. PLoS ONE 11:e0162685-15

Miller JR, Stoner KJ, Cejtin MR, Meyer TK, Middleton AD, Schmitz OJ (2016) Effectiveness of contemporary techniques for reducing livestock depredations by large carnivores. Wildl Soc Bull 40:806-815

Muhly TB, Musiani M (2009) Livestock depredation by wolves and the ranching economy in the Northwestern U.S. Ecol Econ 68:2439-2450

R Core Team (2016). R: A language and environment for statistical computing. $R$ Foundation for Statistical Computing, Vienna, Austria. URL https://www.Rproject.org/

Revelle W (2017) psych: Procedures for Personality and Psychological Research, Northwestern University, Evanston, Illinois, USA, https:/CRAN.R-project. org $/$ package $=$ psychVersion $=1.7 .8$

Rigg R (2001) Livestock guarding dogs: their current use worldwide. IUCN/SSC Canid Specialist Group Occasional Paper.

Rust NA, Whitehouse-Tedd KM, MacMillan DC (2013) Perceived efficacy of livestock-guarding dogs in South Africa: implications for cheetah conservation. Wildl Soc Bull 37:690-697

Scasta JD, Stam B, Windh JL (2017) Rancher-reported efficacy of lethal and nonlethal livestock predation mitigation strategies for a suite of carnivores. Sci Rep 7:1-11

Shivik JA (2006) Tools for the edge: what's new for conserving carnivores. BioScience 56:253-259

Slagle KM (2016) Social and psychological drivers of public involvement in large carnivore management. Ph.D. Dissertation, University of Ohio, Athens

Slagle K, Bruskotter JT, Singh AS (2017) Attitudes toward predator control in the United States: 1995 and 2014. J Mammal 98:7-16

Slagle KM, Bruskotter JT, Wilson RS (2012) The role of affect in public support and opposition to wolf management. Hum Dimens Wildl 17:44-57

Slagle K, Zajac R, Bruskotter JT, Wilson R, Prange S (2013) Building tolerance for bears: a communications experiment. J Wildl Manag 77:863-869

Smith ME, Linnell JDC, Odden J, Swenson JE (2000) Review of methods to reduce livestock depradation: I. Guardian animals. Acta Agric Scand Sect A-Anim Sci 50:279-290
Suryawanshi KR, Bhatia S, Bhatnagar YV, Redpath S, Mishra C (2014) Multiscale factors affecting human attitudes toward snow leopards and wolves. Conserv Biol 28:1657-1666

Suryawanshi KR, Bhatnar YV, Redpath S, Mishra C (2013) People, predators and perceptions: patterns of livestock depredation by snow leopards and wolves. J Appl Ecol 50:550-560

USDA (United States Department of Agriculture) (2015) Sheep and lamb predator and nonpredator death loss in the United States, 2015-\#721.0915. USDA-APHIS-VS-CEAH-NAHMS, Fort Collins

van Bommel L, Johnson CN (2012) Good dog! Using livestock guardian dogs to protect livestock from predators in Australia's extensive grazing systems. Wildl Res 39:220

Wilson MA (1997) The wolf in Yellowstone: science, symbol, or politics? Deconstructing the conflict between environmentalism and wise use. Soc Nat Resour 10:453-468

Young JK, Ma Z, Laudati A, Berger J (2015) Human-carnivore interactions: lessons learned from communities in the American West. Hum Dimens Wildl 20:349-366

Zajac RM, Bruskotter JT, Wilson RS, Prange S (2012) Learning to live with black bears: a psychological model of acceptance. J Wildl Manag 76:1331-1340

\section{Acknowledgements}

C. Mascari helped identify potential participants outside of the core study area and assisted with survey distribution. P. Schirf, R. Kuhnau, J. Munoz, C. Morrison, A. Potash, A. Pozulp, K. Olufs, K. Beattie, E. Gese, S. Breck, and M. Marlow also assisted with survey distribution. A. Pozulp, J. Munoz, and R.S.L. Rodríguez assisted with the Spanish translation of the survey. Thanks to all the participants who filled out and returned surveys. D. Jackson-Smith and Z Ma provided assistance developing and editing the survey. D. Jackson, Z. Ma, and L. Aubry provided edits to the manuscript. This research was supported by the intramural research program of the U.S. Department of Agriculture, National Wildlife Research Center; the Ecology Center and Department of Wildland Resources at Utah State University; and a graduate fellowship provided by the S.J. and Jesse E. Quinney family. Any use of trade, firm, or product names is for descriptive purposes only and does not imply endorsement by the $\mathrm{U}$. S. Government. The findings and conclusions in this publication have not been formally disseminated by the U.S. Department of Agriculture and should not be construed to represent any agency determination or policy.

\section{Author contributions}

DK and JKY conceptualized the study. DK created the survey and was in charge of survey distribution. DK analyzed the data. DK and JKY collaborated to fit results into a theoretical framework and contributed to writing.

\section{Competing interests}

The authors declare no competing interests.

\section{Additional information}

Correspondence and requests for materials should be addressed to J.K.Y.

Reprints and permission information is available online at http://www.nature.com/ reprints

Publisher's note Springer Nature remains neutral with regard to jurisdictional claims in published maps and institutional affiliations.

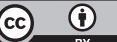

Open Access This article is licensed under a Creative Commons Attribution 4.0 International License, which permits use, sharing, adaptation, distribution and reproduction in any medium or format, as long as you give appropriate credit to the original author(s) and the source, provide a link to the Creative Commons license, and indicate if changes were made. The images or other third party material in this article are included in the article's Creative Commons license, unless indicated otherwise in a credit line to the material. If material is not included in the article's Creative Commons license and your intended use is not permitted by statutory regulation or exceeds the permitted use, you will need to obtain permission directly from the copyright holder. To view a copy of this license, visit http://creativecommons.org/ licenses/by/4.0/.

This is a U.S. government work and not under copyright protection in the U.S.; foreign copyright protection may apply 2019 